\title{
Mecanismos societários e contratuais de gestão das sociedades estatais
}

Marcia Carla Pereira Ribeiro e Gísela Dias Chede

\section{Introdução}

As sociedades estatais, cuja maior ou menor utilização sofre as influências do momento histórico do País, mantêm-se como instrumento disponível ao administrador público para a consecução de objetivo de relevante interesse coletivo ou de segurança nacional. Existe, porém, uma possibilidade notoriamente limitada de investimento de recursos estatais. Quando a atividade a ser desenvolvida puder sê-lo num regime de mercado, ou acompanhada de condições econômicas atrativas à iniciativa privada, a sujeição ao regime jurídico de direito privado, especialmente quanto às sociedades de economia mista, abre um leque de opções de práticas e institutos que podem contribuir para os objetivos pretendidos e, quando possível, conciliar o interesse dos acionistas privados e o do acionista público.

Depois da onda mundial de recurso às privatizações e da incorporação de princípios constitucionais como o da eficiência, cresce em importância a tarefa 
do administrador público de ajustamento da eficácia administrativa à preservação do objeto justificador da criação da estatal. A manutenção e a otimização da sociedade estatal podem ser auxiliadas pela utilização de alguns mecanismos contratuais e societários disponíveis às empresas não estatais e estatais, que podem contribuir para o cumprimento da vocação de as empresas agirem como instrumentos de implementação de políticas públicas de forma ajustada às mais modernas práticas empresariais.

A proposta do artigo é de apresentar alguns desses mecanismos de forma a oferecer ao administrador de sociedade estatal opções compatíveis com o sistema legislativo brasileiro.

\section{Abertura de capital}

Identificada a necessidade de exercício da atividade econômica pelo poder público, a primeira opção a ser feita refere-se à possibilidade de adoção da organização de empresa pública, exclusivamente baseada em investimentos públicos e cuja estrutura permita ao Estado atuar no mercado em caráter de competição com o particular ou não, ou de sociedade de economia mista, o que permitirá a associação ao capital privado, além da competição.

Feita a opção pela empresa pública, é permitida, mediante reforma do seu contrato social, a sua transformação em sociedade de economia mista. Essa transformação deve ser antecedida de autorização legislativa (art. $173 \mathrm{da}$ CF) para a transformação da empresa independentemente de sua extinção e a criação da nova (art. 1.113 do Cciv). Deverá ser acompanhada de transformação de tipo societário (de limitada para sociedade anônima) caso a empresa pública não adote de plano a estrutura de sociedade anônima.

A sociedade de economia mista, por ser constituída sob forma de S/A (art. 236 da Lei de Sociedade por Ações - LSA) poderá adotar a forma fechada ou aberta. A sociedade anônima aberta é aquela que tem seus valores mobiliários (ações, debêntures e outros) registrados para comercialização em bolsa ou balcão. A sociedade anônima fechada não opera no mercado de ações (art. $4^{\circ}$ da LSA).

Uma sociedade anônima pode modificar sua condição de aberta ou fechada depois de sua constituição. Dessa forma, se a finalidade do empreendimento estatal for buscar recursos privados no mercado de ações, poderá a sociedade de economia mista partir para um procedimento de abertura de capital.

A abertura de capital pressupõe a realização de assembléia para que seja tomada a deliberação, antecedida de autorização legislativa quando a lei autorizadora da criação ou transformação da sociedade estatal tenha disposto sobre a sua condição de sociedade fechada. A assembléia deliberará sobre a abertura do capital (art. 122, I, LSA), por maioria simples, seguida do registro da alteração do estatuto na Junta Comercial. No entanto, para que a sociedade anônima possa negociar seus valores no mercado de ações será imprescindível o pedido à Comissão de Valores Mobiliários (CVM) de registro da companhia e a inclusão de seus valores mobiliários no pregão.

Para que seja admitido o registro da companhia na CVM será necessário o encaminhamento dos documentos indicados na LSA (art.82), assim como seguir as demais determinações estabelecidas pela Comissão. São basicamente as mesmas exigências de registro previstas 
para as sociedades anônimas que forem constituídas por subscrição pública: estudo da viabilidade econômica e financeira do empreendimento e estatuto social. Para a negociação dos valores mobiliários em Bolsa de Valores, será necessário também o registro da empresa, depois da autorização da CVM.

Finalizados tais procedimentos, passará a empresa a poder operar no mercado de valores mobiliários para a negociação de suas ações e debêntures (e, embora não usual no Brasil, de seus bônus de subscrição). Por outro lado, o fato de a empresa tornar-se aberta também terá por conseqüência a incidência de maior controle em sua condução, controle exercido especialmente pela própria CVM e pelos acionistas.

Acredita-se que as empresas que operam com a busca de recursos no mercado devem estar sujeitas a controles mais expressivos, seja interno ou externo, em razão do universo de interesses envolvidos e da repercussão de seu resultado. Para as empresas que operam no mercado existe a incidência de normas específicas sobre publicações de balanços, a realização de auditorias e o dever de comunicação.

Por outro lado, a eficiência do mercado de valores mobiliários depende da criação e manutenção de um cenário de relativa estabilidade e previsibilidade para que os potenciais investidores sintam-se atraídos pela proposta de investimento - ou seja, de aplicação de sua poupança - numa atividade que envolve riscos, de um lado, e é um importante promotor da economia, de outro.

Se o propósito for a abertura do capital social, também as sociedades estatais poderão ser criadas ou transformadas em sociedades de economia mista com o já mencionado propósito de possibilitar o acesso aos recursos necessários ao desenvolvimento econômico no mercado. Serão suficientes o acesso a esse conhecimento por parte dos gestores das estatais, a vontade política de incremento da atividade desenvolvida pela empresa, o talento e a eficiência dos administradores em demonstrar as vantagens comparativas de associação do capital do particular ao do Estado, a fim de se possibilitar uma definitiva ruptura da associação entre

“As estatais
beneficiam-se de
um diferencial -a
sua sujeição ao
regime jurídico de
direito privado, no
que se refere aos
mecanismos
societários e
contratuais -, que
deve ser explorado,
de forma a se
otimizar a utilização
dos investimentos
públicos."

atuação estatal e a carência de eficiência administrativa na condução de uma empresa. Evidentemente que a cultura desta passagem do investimento meramente público para o investimento misto estará também condicionada à consagração da autonomia gerencial das empresas estatais, da compatibilização entre a gestão política e a técnica e de uma perspectiva positiva de desenvolvimento econômico do País. 


\section{Aumento de capital, emissão de debêntures e de outras fontes de capitalização}

O acesso ao investimento privado pode ser operacionalizado mediante a adoção de parceiros institucionais, sem a abertura do capital da sociedade, ou por meio da busca de investidores no mercado. O recurso ao mercado pode ocorrer de forma originária quando da constituição da S/A, por subscrição pública, ou depois de realizada a abertura de seu capital, conforme comentários já desenvolvidos.

Estando a sociedade interessada em capitalizar-se para atender às demandas de seu objeto, ou para ampliar sua atuação, o aumento do capital social poderá ser o instrumento mais adequado à percepção dos recursos sem a necessidade de oneração pela via dos recursos financeiros disponíveis no mercado, certamente menos interessantes em razão de seus custos financeiros.

O aumento do capital social é possível na sociedade anônima mediante a realização de reforma do estatuto, antecedida de assembléia com tal propósito, ou mediante decisão do conselho de administração se o estatuto da sociedade contiver cláusula de capital autorizado.

Para as sociedades de capital aberto é interessante que o estatuto contenha cláusula de autorização para o aumento do capital social, independente de reforma do estatuto e da conseqüente convocação de assembléia, respeitados os patamares indicados no próprio estatuto (art. $168 \mathrm{da}$ LSA). Tal cláusula facultará aos administradores da sociedade a escolha da conveniência e oportunidade de lançar ações de forma ágil e autorizada diante de uma situação de boa receptividade do mercado.

Se inexistente a cláusula de capital autorizado, ou se alcançados os limites para aumento lá definidos, será necessária a reforma do estatuto para a promoção do aumento do capital social ou a fixação do limite da autorização.

O aumento do capital social é um recurso a que poderá ter acesso a sociedade, depois de realizados no mínimo três quartos do capital social. A deliberação em assembléia, quando for o caso, dependerá da deliberação da maioria simples dos acionistas titulares de ações com direito a voto e dependerá, como indicado, da reforma do estatuto. A subscrição das novas ações poderá operar-se por subscrição particular - investidores determinados ou subscrição pública, desde que a empresa esteja registrada na CVM.

Quando da realização de aumento de capital, no caso das estatais, a pessoa jurídica de direito público deverá exercer o seu direito de preferência na aquisição das novas ações, a fim de manter o seu percentual de participação na sociedade, que seria modificado em razão das novas ações, devendo, no mínimo, permitir ao Estado que conserve a titularidade da maioria das ações com direito a voto, a fim de garantir-se a condição de sociedade de economia mista do empreendimento.

Para minimizar a necessidade de contrapartida de investimento do majoritário, a fim de assegurar sua posição acionária, pode a companhia operar com a emissão de ações sem direito a voto, na forma de ações preferenciais para as quais o estatuto exclua tal direito (art. $111 \mathrm{da}$ LSA), até os limites estabelecidos na LSA (o art. 15, $\int 2^{\circ}$, estabelece o percentual máximo de $50 \%$ de ações sem direito a voto quanto ao total de ações da companhia, limite aplicável para as sociedades anônimas constituídas posteriormente à vigência da Lei $\mathrm{n}^{\circ}$ 10.303/2001; quanto às sociedades anteriores, vale o estabelecido na redação 
originária da lei, qual seja, admite-se a emissão de dois terços de ações sem direito a voto para um terço de ações com direito a voto).

Além da capitalização por meio da emissão de ações - que traz consigo a necessidade de investimento proporcional da pessoa jurídica de direito público, no que se refere à manutenção do controle e à emissão de ações com direito a voto -, existe a possibilidade de a sociedade emitir outros valores mobiliários. A LSA, além das ações, prevê as debêntures, os bônus de subscrição e as partes beneficiárias como valores mobiliários passíveis de emissão pela companhia.

As debêntures (art. 52 da LSA) são títulos representativos de um empréstimo realizado pelos debenturistas em bloco, que possibilitarão a injeção de capital na empresa. São negociáveis, poderão ter sua emissão assegurada por garantias oferecidas pela companhia e poderão, ao final de seu prazo, atribuir ao titular o direito exclusivo de recebimento dos valores investidos mais a remuneração estabelecida na escritura de emissão das debêntures, ou a faculdade de convertê-las em ações. Sua emissão depende de deliberação em assembléia, e, caso seja da modalidade que permite a conversão em ações, deverá ser assegurado o direito de preferência dos acionistas.

As debêntures podem ser lançadas no mercado interno ou externo e atenderão a sua vocação de instrumento de capitalização da empresa, se o mercado for receptivo ao seu lançamento e a empresa for administrada de forma a permitir aos investidores o resgate prometido ao término dos prazos estabelecidos ou a opção pela conversão das debêntures, quando, então, o debenturista assumirá a condição de acionista da empresa. A confirmação do acerto da opção do investidor pelas debêntures, ao invés de uma outra forma de poupança, conduzirá à criação de um ambiente propício ao investimento da poupança privada na atividade produtiva, em substituição ao investimento financeiro.

Os bônus de subscrição (art.75 da LSA) não são utilizados comumente na prática empresarial brasileira, mas, acredita-se, se firmada definitivamente a tradição do mercado de valores mobiliários brasileiro, o que já não seria sem tempo, poderá assumir papel de destaque como fonte de capitalização das empresas. Os bônus representam um direito de preferência de seu titular quando da futura emissão de novas ações pela companhia. Seu titular paga ou recebe da companhia tais bônus em decorrência de subscrições anteriores, tendo direito assegurado a futura subscrição sem abatimento do preço de emissão das ações ou reembolso pelo valor pago pelos bônus. Evidentemente, o uso corriqueiro dos bônus de subscrição depende do estabelecimento de uma procura acentuada pelas ações de determinada companhia, a ponto de justificar a opção do investidor por pagar pelo bônus (e capitalizar, dessa forma, a empresa) e pagar pela subscrição das ações no momento do efetivo aumento do capital. O direito de preferência dos acionistas será respeitado quando da emissão dos bônus.

As partes beneficiárias (art. 46 da LSA) são valores mobiliários que, a partir da reforma da LSA, ocorrida em 2001, somente podem ser emitidos por companhias fechadas. Atribuem ao seu titular o direito de recebimento de parcela do lucro da empresa sem que ostente a condição de acionista, podem ser negociados pela empresa (funcionando como fonte de capitalização direta), distribuídos em benefício de empregados ou utilizados 
como moeda de pagamento aos credores sociais. Embora restritos às sociedades anônimas fechadas (com o propósito de evitar que parte dos lucros seja deslocada para o titular da parte beneficiária, em prejuízo dos acionistas, nas abertas), poderiam funcionar bem não só como fonte direta de capitalização da empresa, mas como forma de minimização do passivo dela, desde que os credores sociais estejam dispostos a receber tais títulos como forma de pagamento.

Além dos valores mobiliários previstos na LSA, não é estranho, à pratica negocial das companhias brasileiras, a emissão de notas promissórias para serem lançadas no mercado internacional e utilizadas com propósito assemelhado ao das debêntures.

Todos os títulos são negociáveis, vale dizer, podem ser alienados por seus titulares no prazo de suas vigências, são criados para as sociedades anônimas e utilizados por elas como forma substitutiva da busca de recursos no mercado financeiro e podem ser utilizados pelas sociedades de economia mista.

Destaque-se que, dentre as alternativas apontadas, algumas exigirão contrapartida do controlador do Estado e outras não, cabendo aos gestores das sociedades estatais estabelecerem qual a estratégia mais adequada na situação concreta.

\section{A especialização do objeto pela cisão e outros movimentos societários}

Como parte da estratégia administrativa da empresa, incluída a estatal, ou até mesmo como forma de cumprimento de determinação legal, a empresa poderá operar de forma a se adaptar às necessidades do mercado, mediante operação de cisão.
A cisão é prevista como mecanismo de divisão da empresa, por meio da derivação de sociedade ou sociedades, que receberão parcela do patrimônio da empresa originária, assim como se tornarão sucessoras daquela. $\mathrm{O}$ direito conhece duas modalidades de cisão: a total, com o desaparecimento da sociedade originária, e a parcial, com a sua subsistência. A cisão será acompanhada, normalmente, da criação de subsidiárias, o que pressupõe, no caso das estatais, a necessidade de autorização legislativa.

A cisão, ao permitir o desmembramento de uma sociedade, possibilita a adoção de objetos especializados por parte da empresa remanescente e das demais criadas a partir dela. Logo, se o objetivo for mudar o perfil do objeto da empresa, realocando funções em estruturas mais especializadas, a cisão pode ser uma estratégia administrativa. Pode ser utilizada pela estatal organizada sob a forma de limitada, aplicando-se normas do Código Civil (especialmente o art. 1.122), ou sob a forma de S/A, quando devem ser observadas as normas da lei específica (art. 223 e seguintes da LSA). Nas duas formas societárias, a deliberação pela cisão propicia aos sócios que discordarem da estratégia o exercício do direito de retirada, ou seja, de reivindicar da empresa que pague o valor de sua participação societária, possibilitando o seu afastamento do quadro societário. Em razão da diversidade de organização e da forma como previsto nas leis, o direito de retirada tem seu acesso facilitado na sociedade limitada, se comparado ao modelo organizacional da sociedade anônima. Nesta última, busca-se estimular o acionista descontente à alienação de suas ações no mercado, relegando-se a possibilidade de exercício de direito de retirada (com a conseqüente oneração da 
sociedade) para hipóteses bastante excepcionais (art.137, III, da LSA).

As constantes modificações do quadro tecnológico e a ampliação das demandas nestes tempos têm exigido das empresas investimentos que possibilitem a manutenção dos níveis de competitividade, de recursos e de estratégias de investimento, voltados ao aprimoramento dos parques industriais com acréscimo de produção. Mais especialmente nas empresas estatais de fornecimento de serviços públicos, no campo do saneamento e energia elétrica, como exemplo, é possível visualizar-se a perspectiva de custos em investimentos de infra-estrutura industrial, assim como sua vocação de universalização de fornecimento - com aumento de demanda.

A especialização da atividade da empresa mediante cisão pode minimizar a dificuldade administrativa de alocação de recursos, atribuindo-se a cada núcleo de atividade condição de entidades autônomas, coordenadas pela empresa mãe.

Para que não exista uma completa dissociação entre as empresas derivadas da cisão e a cindida, tal movimento societário poderá vir acompanhado da formação de um grupo de sociedades, de forma a garantirse uma condução harmoniosa dos empreendimentos que mantêm conexões. É comum, quando da formação dos grupos, optar-se pela criação ou manutenção de uma empresa bolding, que será a titular do controle das demais empresas componentes do grupo, mantendo, em paralelo à especialização dos objetos, uma condução coordenada, desde que compatibilizada com a autonomia gerencial essencial ao bom resultado da opção pela cisão.

A cisão, que já foi utilizada como modelagem preparatória às privatizações, v.g. as empresas que compunham o Sistema Telebrás, pode agora servir também de instrumento de estabelecimento de um novo modelo gerencial para as estatais, que permita a busca da eficiência pela especialização do objeto, associada à manutenção da coordenação unitária, em beneficio da expressão do interesse público que motiva a sua existência.

Além da cisão, a lei faculta às empresas adotar um processo de fusão ou de incorporação. $\mathrm{Na}$ fusão, duas ou mais empresas desaparecem para o surgimento de uma

"A cisão, utilizada

como modelagem

preparatória às

privatizações, pode

agora servir também

de instrumento de

estabelecimento de

um novo modelo

gerencial para as

estatais, que permita

a busca da eficiência

pela especialização

do objeto."

terceira, que será sucessora das desaparecidas. A incorporação caracteriza-se pela existência de uma empresa (que pode ser até criada para essa finalidade) que absorve uma ou mais empresas que desaparecem, tornando-se sucessora da ou das desaparecidas. Como as empresas estatais têm sua existência condicionada aos termos da autorização legislativa, quando estiver em questão o desaparecimento de uma estatal, 
haverá necessidade da autorização. Também a fusão e a incorporação precisam ser deliberadas pelos acionistas, que atribuem o direito de retirada, com as restrições estabelecidas em lei.

A estatal, pelo fato de adotar uma forma societária, poderá ter acesso aos movimentos societários e instrumentos contratuais, da mesma maneira como a eles poderá recorrer uma empresa de capital exclusivamente privado. Mobilidade esta que somente estará disponível porque a opção da administração pública terá sido a organização nos moldes empresariais.

A mobilidade, possibilidade de adaptação às necessidades do mercado, e o acesso aos movimentos societários de especialização do objeto (cisão) ou de sua concentração (fusão e incorporação) característicos das empresas trazem consigo uma capacidade adaptativa incomum à prática da administração pública e podem contribuir, de forma essencial, à otimização da prática empresarial estatal, desde que utilizados com o objetivo de aperfeiçoamento de suas atividades e de forma planejada.

\section{Aspectos de gestão}

Num dado momento, pode interessar à administração pública diminuir seu nível de investimento numa empresa ou buscar um parceiro estratégico para que ele cresça não apenas injetando capital, como também propiciando acesso a tecnologia ou a experiências administrativas privadas. No entanto, há uma dificuldade doutrinária e jurisprudencial na assimilação da possibilidade de partilha do poder de controle nas sociedades estatais de economia mista.

Como modalidade de partilha de poder, existe a via do acordo de acionista e da emissão de ações com poderes especiais, por ocasião do afastamento estatal por desestatização ou por opção estatutária.

Por outro lado, a tendência para as sociedades estatais será de adaptação ao regime de governança corporativa e sua conseqüente profissionalização nas funções de gerência.

\section{Acordo de acionista}

A aceitação ou não da possibilidade de o Estado acionista vincular-se a um acordo de acionistas numa sociedade de economia mista tem gerado controvérsias.

O acordo de acionista é um negócio jurídico parassocietário, previsto na LSA, mas passível de ser utilizado também na sociedade limitada, que permite aos acionistas a regulação do exercício de voto e da negociabilidade de suas ações. Muito embora, a rigor, o acordo de acionistas possa ser utilizado para o disciplinamento de qualquer conduta dos acionistas, para a lei, e a fim de que sejam aplicáveis as normas específicas quanto a sua execução, poderá versar sobre "compra e venda de suas ações, preferência para adquiri-las, exercício do direito a voto, ou do poder de controle" e será necessariamente arquivado na sede da empresa (art. 118 da LSA). A redação da LSA, modificada pela Lei $\mathrm{n}^{\circ} 10.303 / 2001^{1}$, consagrou uma conseqüência que já não se negava aos acordos de acionistas, a de estabelecerem a condição de controle numa S/A, como forma regular do poder de condução dos negócios da empresa.

No caso das sociedades de economia mista, a utilização do acordo de acionistas encontra resistências da parte dos que entendem que sua caracterização depende da utilização de prerrogativas especiais e constante interesse na condução da empresa para o cumprimento da finalidade que 
orientou a sua criação, o que seria incompatível com o interesse dos acionistas particulares na condução para o lucro (Figueiredo, 2003).

A LSA efetivamente estabelece, em seu art. 237, que a "companhia de economia mista somente poderá explorar os empreendimentos ou exercer as atividades previstas na lei que autorizou a sua constituição", do que se infere a essencialidade do controle da empresa pelo Estado. Nessa linha de pensamento, o acordo de acionistas que dispusesse sobre o exercício do direito de voto na sociedade de economia mista estaria contrariando a natureza estatal da entidade.

No entanto, existe a possibilidade de se chegar a uma conclusão diversa a partir da noção de controle. Há a percepção do controle absoluto, exercido de forma estável e única pelo controlador ou grupo de controle, mas igualmente uma possibilidade de apreensão de controle partilhado decorrente de mais de uma fonte de comando.

Se a idéia estiver centrada no controle absoluto, na sociedade estatal qualquer cláusula ou condição estabelecida em acordo de acionistas que diminua ou ateste o caráter não absoluto do exercício do poder pelo acionista Estado terá por conseqüência a descaracterização da condição de sociedade de economia mista para a empresa em questão, o que dependeria, caso fosse a vontade da administração pública, de autorização legislativa.

Se o pressuposto for alterado e for levada em consideração a tendência de se exigir das sociedades, ao lado da transparência de sua gestão, a adoção de práticas mais participativas das diversas categorias de acionistas, a conclusão será diferente daquela anteriormente identificada.

A limitação dos poderes do controlador, como forma de equilíbrio entre controle e autonomia na relação entre o Estado e suas empresas, aparece na celebração de contratos de gestão com os dirigentes das empresas, na terceirização da gerência do ente estatal e na escolha de um sócio estratégico com a finalidade de ajudar na reestruturação e gestão da empresa (SundFeld, 2000).

Quando a opção for pela inclusão de um sócio estratégico, o acordo de acionistas será um instrumento indispensável ao estabelecimento do equilíbrio interno, uma vez que o Estado necessariamente preservará a condição de titular da maior parte das ações com direito a voto. A previsão de atribuição de poderes para o acionista estratégico, como a indicação de gestores da empresa, ao contrário do precedente do Estado de Minas Gerais, não significa necessariamente a descaracterização da condição de sociedade estatal da empresa ${ }^{2}$.

A via do acordo é uma forte aliada à busca do investidor estratégico, que vem para a sociedade como fonte de capitalização da empresa e também com a experiência, a qual deverá ser exigida no edital de alienação das ações destinadas ao novo investidor. Certamente que o objetivo de associação de investimento e tecnologia somente será atingido se o investidor privado tiver a garantia de participação efetiva na condução do negócio, junto com o Estado, a fim de propiciar a desejada troca de experiência e a oxigenação na condução dos negócios.

Para que seja afastado o risco de desvirtuamento da sociedade estatal, em razão da partilha de controle, podem-se adotar medidas bastante simples, como fazer constar do acordo, por exemplo, que as medidas administrativas que puderem colocar em risco o interesse público que justificou a criação da sociedade estatal não estarão incluídas no ajuste deliberativo ou, 
ainda, estabelecer o poder de veto do Estado em determinadas questões essenciais à manutenção da condição de sociedade estatal. Por outro lado, diante da eventual prevalência do interesse privado incompatível com o interesse público, existem defesas de ordem societária que podem ser tomadas pelo Estado acionista, como medidas de afastamento de deliberações decorrentes do exercício abusivo do poder de deliberação. Não parece que a existência de acordo de acionistas firmado pelo acionista Estado e por particulares seja, por si só, elemento descaracterizador da condição de sociedade estatal; é, no entanto, essencial à sedução do investidor privado interessado na melhor condução administrativa possível do empreendimento.

Se o Estado busca exclusivamente o interesse público no exercício de uma atividade econômica, pela lógica não estará comportando-se de forma a atrair o investidor privado, o que, aliás, é característico de uma sociedade de economia mista, conduzindo a prognósticos nada animadores quanto à escolha do modelo associativo público/privado, sendo mais conveniente a adoção da empresa pública, com as vantagens e desvantagens dessa escolha (RIBEIRO, 2001).

Lembre-se de que, hoje, a idéia de controle não se limita à titularidade da maior parte das ações com direito a voto e tampouco ao efetivo exercício do poder de deliberação, uma vez que o condicionamento da aprovação de determinados temas numa sociedade ao poder de veto de parte do acionista, ou à exigência de quórum mais elevado, faz sentir a existência de uma outra forma de controle, até mesmo por parte da minoria.

Para que se demonstre que o risco da perda do poder absoluto do controlador (inclusive o Estado) está recepcionada pela ordem jurídica vigente, interessante considerar que a LSA, no art. 111, \ $1^{\circ}$, sanciona a omissão na distribuição de dividendos fixos ou mínimos pela companhia com a atribuição de poderes de voto para ações destituídas de tal prerrogativa pelo estatuto, as ações preferenciais.

Portanto, o poder de controle não deve ser tido como absoluto, nem mesmo na sociedade estatal, existindo mecanismos capazes de garantir a manutenção do interesse público que motivou a criação da sociedade de economia mista, ainda que se opte pela busca de um parceiro estratégico e a elaboração de um acordo de acionistas.

\section{Golden share}

A golden share é uma modalidade de ação que atribui ao seu titular poderes especiais. No direito inglês, associada ao processo de desestatização, encontrou sua justificativa "nos casos em que se entendia que o interesse público permanecia latente na empresa privatizada" (CHIRILlo, 1995). $\mathrm{Na}$ França, ela recebeu a denominação action spécifique, subordinando-se a sua criação às razões de interesse nacional (Chirillo, 1995).

No Brasil, pelo art. 18 da LSA, o estatuto pode atribuir poderes políticos aos acionistas preferencialistas ao garantir direito de eleição, em votação em separado, de um ou mais membros da administração da empresa, como também o direito de veto na hipótese de proposta de alteração estatutária. Na sociedade fechada, art. 16, III, da LSA, o estatuto poderá conferir a determinadas classes de ações o direito de voto em separado para o preenchimento de cargos na administração da empresa. Numa e noutra hipótese, o estatuto, ao 
optar por conferir o poder de eleição de membros da administração ou o direito de veto em determinadas deliberações, estará caracterizando tais ações como golden share.

No âmbito das privatizações, a Lei $\mathrm{n}^{\circ} 8.031 / 90^{3}$ explicitou a possibilidade da criação de ações dessa natureza nas empresas privatizadas, especificando que estas poderiam ser detidas exclusivamente pela União e que o seu poder estaria restrito ao veto em determinadas matérias. Com o advento da Lei $\mathrm{n}^{\circ} 9.457 / 97^{4}$, que revogou as disposições da Lei $n^{\circ} 8.031 /$ 90, as prerrogativas conferidas às golden shares ampliaram-se para além do direito de veto, passando a incorporar, genericamente, poderes especiais em determinadas matérias.

Mais recentemente, a matéria recebeu especial tratamento na já citada Lei $\mathrm{n}^{\circ} 10.303 / 2001$, a qual introduziu o $\int 7^{\circ}$ no art. 17 da LSA com a seguinte redação: "Nas companhias objeto de desestatização poderá ser criada ação preferencial de classe especial, de propriedade exclusiva do ente desestatizante, à qual o estatuto social poderá conferir os poderes que especificar, inclusive o poder de veto às deliberações da assembléia geral nas matérias que especificar".

Além de atribuir contornos mais precisos à golden share, quando aplicada às empresas privatizadas, o dispositivo legal estendeu a sua utilização aos estados e municípios, diversamente das Leis $\mathrm{n}^{\circ} 8.031 / 90$ e $\mathrm{n}^{\circ} 9.491 / 97^{5}$, que restringiam esse direito à União.

A outorga de poderes especiais conferidos à golden share pode, teoricamente - a depender da gradação dos poderes conferidos ao titular -, ter por conseqüência o deslocamento do controle da companhia, podendo o seu detentor vir a ser equiparado ao controlador, especialmente no que se refere à condução dos negócios da empresa, seja mediante indicação de administradores, seja pelo exercício do direito de veto.

A sistemática da golden share dispensa o titular de altos investimentos na empresa, ao mesmo tempo em que assegura, em maior ou menor grau, uma efetiva participação na tomada de decisões. $\mathrm{Na}$ prática, pode significar a manutenção do poder, posteriormente a uma abertura do
"A profissionalização da gestão das estatais deve estar associada à valorização do quadro de carreira dos funcionários e atenta à vinculação da atividade da empresa às políticas públicas e aos planos de governo." capital para investimento externo, tendo previsão expressa, conforme visto, na hipótese de desestatização de empresas, mas podendo ser adotada no estatuto da sociedade anônima, independentemente de lei autorizadora especial.

Adotando-se o conceito de sociedade estatal como aquela na qual existe o poder de controle do Estado, este nem ao menos precisa decorrer da titularidade da maior 
parte das ações com direito a voto, podendo ser interessante para o poder público titularizar, inclusive por meio de subsidiárias, ações especiais que possibilitarão menor investimento sem prejuízo da opção de regulação da atividade econômica na situação concreta.

\section{Profissionalismo na gestão e aspectos de governança corporativa}

A excessiva, e muitas vezes equivocada, ingerência política na condução dos negócios das empresas estatais foi, em grande medida, a responsável pela recente crise do setor e um dos fatores justificadores da onda desestatizadora.

Por óbvio, a perspectiva de que os rumos de uma sociedade estatal possam ser constantemente alterados, de acordo com o arbítrio dos governantes que se sucedem, afugenta o investidor privado, exatamente por não propiciar ao empreendimento o mínimo de estabilidade que o cálculo de risco exige. Nesse passo e considerando que a empresa estatal não é instituída para satisfazer a vontade de governos transitórios, mas para atender aos interesses permanentes do Estado, o profissionalismo na gestão e a adoção de práticas de governança corporativa apresentam-se como alternativas bastante viáveis para a solução desse problema.

Certamente a indicação dos gestores de uma sociedade estatal representará sempre um dilema compreensível para o administrador público. Existe a tendência de utilização dos cargos disponíveis nas estatais para alocação de agentes políticos que não estejam ocupando outros cargos, assim como a possibilidade de escolha pelo perfil de afinidade com as políticas macroeconômicas, ao se pensar numa grande estatal fornecedora de infraestrutura, por exemplo. Existe ainda a possibilidade da opção pelo perfil técnico do indicado.

Uma estratégia possível e que contribuiria para a otimização da gestão empresarial pública poderia estar pautada nos seguintes critérios: nas pequenas empresas estatais, o aproveitamento do quadro técnico próprio, o que funcionaria, inclusive, como forma de estímulo aos funcionários de carreira, com ênfase na possibilidade de aproveitamento em cargos de gestão; nas médias e grandes empresas, nos cargos de gestão executiva, também a ênfase no critério técnico e, preferencialmente, na própria carreira, reservando-se aos cargos de direção-geral a escolha, ou de um técnico estranho ao quadro político (se a situação concreta estiver por exigir um processo de reestruturação empresarial ou mudanças), ou um agente político em sintonia com as políticas públicas voltadas à área (quando a empresa for sujeito ativo na implementação de determinado plano de governo). Portanto, a profissionalização da gestão das estatais deve estar associada à valorização do quadro de carreira dos funcionários e atenta à vinculação da atividade da empresa às políticas públicas e aos planos de governo.

No campo dos interesses, ao se administrar uma sociedade, especialmente aquela que opera com valores mobiliários no mercado, não será apenas o interesse dos acionistas que deverá ser considerado, mas igualmente outros interesses internos e externos vinculados, de alguma forma, com o resultado da empresa. Com a finalidade de se possibilitar a harmonização desses diversos interesses, algumas práticas cada vez mais se consolidam como desejáveis estratégias de delineamento da melhor estratégia de gestão de uma empresa. Podem ser destacados cinco níveis de boas práticas de governança corporativa: transparência (disclosure), eqüidade 
(fairness), prestação de contas (accountabilitty), cumprimento das leis (compliance) e ética (Melo, 2005).

A transparência pode ser relacionada à prática de deixar claro para o mercado e para todos que tenham interesse no empreendimento qual o nível de interesse dos administradores em relação à empresa, ao se considerar a possibilidade de tais administradores serem acionistas ou investidores dela. Ao invés de negar-se a possibilidade de negócios internos, que poderiam ser vantajosos para a empresa e para o administrador/sócio, ou ainda de criarem-se leis que impossibilitem tal situação - que facilmente poderia ser contornada pela adoção de negociações transversas ou por interposta pessoa -, opta-se por admitir tal possibilidade, acompanhada, no entanto, de divulgação por meio da publicidade hábil, a tornar a informação acessível e eventualmente contestável pelos interessados.

A transparência que se quer exigir das empresas não é, em absoluto, estranha à atividade do poder público, sujeita, em razão de sua própria natureza, a múltiplos princípios e controles. A Constituição brasileira, em seu art. 37, já prevê como princípios aplicáveis à administração pública, juntamente com a legalidade, impessoalidade, moralidade e eficiência, o princípio da publicidade.

Logo, a utilização da publicidade como instrumento associado à gestão de uma empresa poderá ser, e provavelmente será, adotado pela empresas estatais, existindo proposta que prevê regulamentação nessa área, assim como pelas empresas que pretendam ter seus valores negociados no Novo Mercado instituído na Bovespa.

A eqüidade significa admitir que, internamente, o tratamento atribuído aos acionistas de uma empresa, em que pese a diversidade de direitos decorrentes das características dos valores mobiliários de sua titularidade, não pode justificar ganhos ou perdas excessivas de determinada categoria em detrimento de outra.

Ela pode ser interpretada ainda como a consagração da valorização de todos os interesses que transitam ao redor da empresa, desde os internos - diversas categorias de acionistas, investidores, trabalhadores - até os externos fornecedores, consumidores, meioambiente, concorrência -, como instrumento de harmonização que contribuirá para a maior duração possível do empreendimento.

Nesse particular, as sociedades estatais, especialmente aquelas de economia mista, devem exercitar, de forma especial, a habilidade de compatibilização do interesse público que motivou a criação e motiva a permanência do investimento público com aquele dos investidores privados, normalmente pautado na busca da melhor rentabilidade. A diversidade de interesses e de grau de interesses não é particular às sociedades estatais, conforme indicado. Numa sociedade privada, há também interesses diversos que, eventualmente, podem estar contrapostos, como, por exemplo, interesse dos fundadores, se comparado ao dos acionistas especuladores, os que procuram um investimento com rentabilidade em médio e longo prazo, se comparado com os que buscam a liquidez e rentabilidade imediatas.

A existência de conflitos de interesse pode ser considerada natural a qualquer atuação que envolva mais de um participante, especialmente ao se considerarem as diferentes oportunidades de participação e investimento que serão disponibilizadas aos interessados no decorrer da 
vida de uma empresa e que atrairão pessoas dos mais diversos perfis.

A sensação de justiça que a atuação pautada na eqüidade pode trazer para os acionistas é imprescindível à criação de um ambiente estável fortemente favorável à estabilização da atividade empresarial.

Em termos normativos, a reintrodução, no ordenamento jurídico, da possibilidade de os minoritários se beneficiarem (de parte) do ágio pago quando da alienação do controle de uma empresa compatibiliza-se com a busca da eqüidade (art. 254-A da LSA). Anote-se que tal benefício havia sido revogado, na sua versão originária do art. 254 da LSA, pela Lei no 9.457/97, como estratégia de valorização das ações do Estado, no auge da política de desestatização. A revogação desobrigava o potencial comprador das ações que garantiam o controle do Estado do pagamento de ágio aos demais titulares de ações com direito a voto que não estivessem incluídas no grupo de ações de controle, garantindo uma melhoria no limite de oferta de compra, mas contrariando qualquer sentimento de segurança para potenciais candidatos à associação ao capital público, diante do precedente de modificação da legislação para adequação ao interesse de maximização do valor das ações do controlador Estado. Vale dizer, uma cultura que se pretenda de estímulo à associação do capital público e privado não combina com medidas modificativas de direitos que atinjam as categorias privadas de investidores, sendo a eqüidade um ideal facilitador da otimização administrativa das empresas, em geral, e da sociedade estatal, em particular.

A prestação de contas como instrumento de publicização da conduta administrativa de uma empresa é dever dos administradores consagrados, ao menos em seus aspectos mínimos obriga- tórios, pela lei. Atualmente, em termos de implementação de governança corporativa, a questão pode ser focada em quem será o destinatário da prestação de contas: se, em conformidade com a doutrina de origem norte-americana, apenas os acionistas, de forma mais direcionada, ou se outros grupos, tendência européia, como o dos empregados. $\mathrm{Na}$ sociedade estatal, com exceção da política de estratégia comercial e industrial da empresa, que, eventualmente, não poderá estar contemplada numa prestação de contas, sob pena de quebra do necessário sigilo, outros dados que possam ser acessíveis não só aos acionistas, como também à população em geral poderiam ser disponibilizados como forma não só de estímulo à participação de interessados com a garantia de transparência que tal prática comporta, mas também como forma de expressão de uma prestação de contas pública quanto à utilização dos recursos públicos. Por outro lado, a administração pública e, inclusive, suas empresas estão ordinariamente sujeitas a controles, como aquele exercido pelo Tribunal de Contas, pelo Ministério Público, via ação civil pública, ou pelo cidadão, via ação popular. Novas e adequadas normas de prestação de contas para as estatais seriam compatíveis com a proposta de aperfeiçoamento de sua gestão.

O cumprimento da lei, que pode ser identificado como um dos indicadores de governança corporativa, evidentemente não causa qualquer estranheza no campo das sociedades estatais. O princípio da legalidade atinge e norteia a utilização das estatais, inclusive ao condicionar a sua própria criação à existência de lei autorizadora assim como sua extinção, que dependerá da norma. Além das normas constitucionais e infraconstitucionais aplicáveis às sociedades em geral, aquelas 
aplicáveis exclusivamente às estatais - de direito administrativo, por exemplo -, o cumprimento da lei como princípio de governança corporativa para as estatais deve estar acompanhado de uma visão restritiva quanto à possibilidade de alteração da lei em benefício da pessoa jurídica de direito público. Ao optar por atuar empresarialmente, deve o Estado submeter-se às normas societárias aplicáveis às demais empresas e, em benefício da almejada estabilidade econômica, esquivar-se de reformar a lei, modificando normas já consagradas em benefício próprio - como o precedente de revogação e depois restabelecimento do benefício da extensão do ágio aos ordinaristas minoritários em favorecimento do Estado. Ou seja, a cultura de aceitação e proveito dos benefícios da utilização das sociedades estatais estará diretamente ligada não apenas ao cumprimento da lei, como também à sua estabilização.

A ética, também apontada como primado do estabelecimento da governança corporativa para as sociedades em geral, evidentemente se presta também às sociedades estatais. Toda administração pública, não só a empresarial, deve estar assentada em princípios éticos. A moralidade é também um dos princípios a serem exigidos do administrador público e que precisa ser adotado de forma ilimitada pelos administradores das empresas privadas e estatais.

Por conseqüência, a adoção de práticas de governança corporativa pelas sociedades estatais, além de compatibilizar-se com a natureza de tais sociedades, conforme se procurou demonstrar anteriormente, certamente contribuirá com as novas propostas de gestão das estatais, a fim de consagrá-las como instrumento de implementação de políticas públicas perfeitamente adequadas ao intento de otimização no emprego dos escassos recursos públicos.

\section{O caso Copel}

Com a finalidade de ilustração quanto à aplicabilidade dos mecanismos societários pela sociedade estatal, serão abordados alguns aspectos relacionados à COPEL Companhia Paranaense de Energia.

\section{A titularidade do capital social}

O capital inicial da empresa foi de 800 milhões de cruzeiros - atualizados para novembro de 2005 remontariam a mais de $\mathrm{R} \$ 62$ milhões - e hoje alcança o valor de $\mathrm{R} \$ 3,48$ bilhões $^{6}$. Conforme a Ata da Assembléia Geral de Constituição, de 28 de março de 1955, o Estado do Paraná subscreveu as 320 mil ações preferenciais criadas e 479.990 ordinárias. As restantes dez ações ordinárias foram subscritas por seis pessoas naturais, subscrevendo quatro delas duas ações cada uma e as duas outras, ainda estudantes, uma ação cada uma. O estado integralizou suas ações em bens avaliados no valor de Cr\$25.843.500,00 e Cr\$ 54.155.500,00 em dinheiro. Os bens consistiam em equipamentos para a geração de energia, situados em Campo Mourão, Bairro Alto, Paranaguá e Morretes.

Os primeiros dez acionistas diferentes do governo do estado, em 1998, já superavam 10 mil e alcançavam o percentual de $10 \%{ }^{7}$. Essa multiplicação ocorreu devido aos programas de extensão de rede. Quem aderia recebia ações, o que foi até 1972; houve ainda as cooperativas de eletrificação rural, com ações, que, ao serem dissolvidas, transferiram seus ativos aos cooperados.

Houve também o programa Seu Talão Vale Um Milhão, pelo qual a Companhia 
de Desenvolvimento Agropecuário do Paraná (Codapar) trocava notas fiscais por ações de companhias do estado, entre as quais as da Copel. Também o Imposto Único sobre Energia Elétrica, uma espécie de empréstimo compulsório arrecadado pelos municípios, vinha à Copel como investimento, traduzido em ações para os municípios. Tais eventos vão até a década de 1990.

Ainda, pela encampação das pequenas concessionárias que possibilitaram à empresa grande expansão do setor energético no estado, vieram acionistas privados, porque os acionistas das encampadas passaram também a ser acionistas da Copel.

Além disso, o estado caucionou ações junto ao BNDES. Criou-se uma empresa, Paraná Investimentos, sociedade de propósito específico, na qual o estado passava ações para venda em block trader, que permitiu a emissão de debêntures conversíveis em ações da empresa.

Em função desses processos, em 1998, o estado detinha 90\% das ações. Após deliberação pela venda de parte de suas ações, ele ficou somente com o controle, com cerca de $58 \%$ das ações com direito a voto, e não possuindo mais nenhuma ação preferencial.

\section{Abertura de capital}

A evolução da empresa é marcada, entre outros aspectos, pela construção de usinas visando a minimizar a dependência de energia importada. A década de 1960 foi assinalada pelo atendimento ao norte pioneiro e ao sul do estado. Nos anos 70, foram atendidos o oeste e o sudoeste. Em 1980, é inaugura a usina de Foz de Areia, maior geradora da Copel, e, nesta década, há grande trabalho de eletrificação rural e atendimento a pessoas carentes. Também há a construção de Segredo e o inicio das tratativas para a construção da usina de Salto Caxias, empreendimentos consolidados nos anos 90, inaugurado precisamente em 1999.

A evolução estatutária da Copel guarda estreita relação com a conjuntura econômica, embora marcada por uma condução altamente técnica de seus planos e estratégias. Estes possibilitaram à companhia condições de obter resultados superavitários, mesmo quando outras companhias similares não o conseguiram, e vários prêmios de qualidade, e o Estado do Paraná chegou a ter a comodidade de praticamente não sentir os efeitos do recente racionamento de energia elétrica.

Dentro dessa linha de condução planificada, com investimentos estratégicos, a necessidade de recursos para investimento determinou a abertura do capital em 1994 ao mercado de ações. O objetivo era alcançar o mercado internacional, o que veio a efetivar-se em 1998 com o lançamento de ações no mercado americano. A abertura de capital possibilitou um grande salto de investimentos e resultados para a companhia - que, à época, foi interpretada, em parte, como forma de privatização da empresa.

Cronologicamente, antes da oferta internacional, por diversos meios já havia ações da Copel em poder de outras instituições públicas e pessoas naturais, as quais, com abertura de capital, puderam ser negociadas em bolsa. Exemplo disso é um block-trade de ações de titularidade do BNDES, em cujo edital de leilão se admitiu a interferência de terceiros vendedores e titulares de ações (CASAgrande NeTO, 2000). Posteriormente, operou-se a abertura para o mercado brasileiro e norte-americano.

A estrutura societária de empresa mista de capital aberto mostrou-se apta a 
responder à necessidade de vultosos recursos para os programas de transmissão de energia elétrica, distribuição de gás e expansão da geração, especialmente a usina de Salto Caxias. A economia brasileira sofria aceleração e queda da inflação e os agentes econômicos optavam por investimentos de curto prazo e alta liquidez, a mesma estratégia adotada pelas instituições financeiras.

Paralelamente, o desequilíbrio das contas públicas fazia o governo ir ao mercado com juros de $20 \%$, disputando a poupança com as empresas. A solução para financiamento em longo prazo seria via BNDES, opção também restringida dada a política de contingenciamento de crédito ao setor público adotada pelo governo federal.

De outro lado, o mercado acionário apresentava indícios favoráveis, notadamente com relação ao setor elétrico, devido à fixação dos níveis das tarifas para o serviço público de energia elétrica, à extinção do regime de remuneração garantida e à busca de reestruturação do setor elétrico, entre outras.

Assim, para possibilitar às empresas irem ao mercado sem risco de diluição do seu patrimônio foi necessária a transformação da companhia em capital aberto ${ }^{8}$.

As providências foram simples, iniciando pelo registro na Comissão de Valores Mobiliários e pelas alterações estatutárias, que aguardaram a assembléia geral ordinária de março de 1994. A transformação beneficiaria todos os atuais acionistas, especialmente as prefeituras, com aumento de liquidez e possível valorização das suas ações.

\section{A venda das ações do estado}

No compasso da abertura do capital, pela necessidade de investimentos objetivando manter a capacidade de atendimento no Estado, principalmente quanto à geração de energia, em razão do crescimento da atividade econômica no estado, foi editada a Lei Estadual $\mathrm{n}^{\circ} 10.702^{9}$, de 30/12/93, autorizando o governo a vender ações da Copel, segundo parâmetros que indicam o claro objetivo de se obterem recursos para investimentos na própria empresa. Poderiam ser alienadas: a) todas as ações sem direito a voto, em nome do estado; b) até $40 \%$ de todas as ações ordinárias do estado; e c) todas ações (com e sem direito a voto) emitidas em nome do Fundo de Desenvolvimento Econômico do Estado, administrado pelo então Banestado.

A lei determinava o modo como deveriam ser investidos os recursos obtidos com a venda, nos seguintes termos: 1) 10\% em casas populares; 2) 25\% na Ferroeste; e 3) $65 \%$ na própria Copel, em sistemas de geração, transmissão e distribuição de energia, e assegurava que as necessidades efetivas deste último investimento determinariam o fluxo do parcelamento das vendas. Tal reinvestimento na própria Copel foi importante fator para a valorização das ações.

Havia ainda a proibição de efetivar os procedimentos de venda, se a avaliação específica, destinada a cada operação, indicasse para o lote preço mínimo inferior a 90\% do patrimônio líquido nas ações preferenciais e 100\% nas ações ordinárias.

Outros detalhes eram que as operações seriam levadas a cabo pela Banestado Corretora, uma comissão de cinco membros do Poder Legislativo acompanharia as operações e haveria a contabilização dos recursos da venda em conta gerida pela Copel, denominada "Fundo de Investimentos Energéticos", até 
a sua conversão em ações pelo Estado do Paraná, em futuras subscrições.

$\mathrm{Na}$ época, o reinvestimento dos 65\% apurados com a venda das ações na própria Copel era apontado como fundamental para o início das obras da usina de Salto Caxias, a fim de se evitar racionamento de energia no final da década. Além disso, a venda possibilitaria o efetivo ingresso, ainda em 1994, de recursos necessários para a contrapartida do estado em financiamentos em organismos internacionais ${ }^{10}$.

Posteriormente, essas diretrizes legais foram alteradas. Primeiramente houve autorização para o governo do estado vender, dar em caução e/ou oferecer, como garantia de operações de crédito, em financiamentos e operações de qualquer natureza, as ações da Copel ${ }^{11}$, limitadas essas operações de crédito a 500 milhões de reais.

As vendas ou cauções passam a ser parceladas conforme as necessidades de investimentos do estado, e não mais pela demanda de investimentos da Copel.

De qualquer modo, no final de 1997 , conforme informações do site da Copel, e no ano de 1998, conforme informações correntes, a empresa ingressou na bolsa americana e atualmente seus títulos também são negociados no mercado europeu.

\section{Acerto na conta de resultados a compensar}

O processo de abertura do capital importa transparência para qualquer empresa, como parte da estratégia de governança corporativa para conquistar credibilidade no mercado acionário, e algumas mudanças estruturais se fazem necessárias. Não foi diferente para a Copel, que, no entanto, não teve necessidade de largas alterações estatutárias para poder apresentar-se ao mercado, já que detinha um porte significativo e a organização profissionalizada. Ainda assim foram necessários alguns ajustes, como aqueles relacionados à Conta de Resultados a Compensar.

A situação pode ser assim resumida: a tarifação do sistema elétrico tinha uma cláusula ouro, pela qual o nível de remuneração tarifária da empresa seguiria o valor desse ativo, sendo altamente favorável às empresas estrangeiras. $\mathrm{O}$ Código Nacional de Águas, de 1934, introduziu "o regime tarifário pelo custo do serviço, com uma taxa interna de retorno máxima permitida às concessionárias de $10 \%$ sobre o custo histórico dos ativos" ${ }^{\prime 2}$, e as sucessivas políticas para fixação das tarifas em atendimento ao percentual estabelecido não foram eficazes para cobrir o custo de serviço.

Em 1971, essa taxa foi aumentada para $12 \%$, o que garantiu um retorno mínimo de $10 \%$, ficando estabelecido que "eventuais insuficiências ou excessos de remuneração, apurados pelo poder concedente junto a cada concessionária, durante as prestações de contas anuais, passariam a ser registrados contabilmente na Conta de Resultados a Compensar $(\mathrm{CRC}) " 13$.

Assim, por vários fatores e acontecimentos econômicos, a evolução da política tarifária gerou déficits para algumas concessionárias e superávits para outras. $\mathrm{O}$ resultado final desse processo é que o poder concedente tinha débito com as concessionárias e passaram a ser feitas compensações com ativos da União, inclusive possibilitando que fossem compensados débitos do estado.

Apesar de alguns significativos encontros de contas, a dívida da União aumentou, por inúmeros fatores da história 
tarifária. Em 1993, em razão de grande encontro de contas entre as empresas credoras e devedoras, concluiu-se que a Copel era credora e importava contabilizar esses valores para permitir os resultados positivos esperados com a venda de parte da participação acionária do estado.

O saldo remanescente das CRCs era de aproximadamente 340 milhões de dólares e era importante definir contratualmente a forma como o estado devolveria à Copel esses valores que lhe seriam repassados, dada sua grande influência no valor das ações ${ }^{14}$.

A não-incorporação expunha o governo politicamente, pois repassaria aos compradores das ações um valor a ser realizado a longo prazo, sujeitando-se a questionamentos judiciais. Já o impacto da incorporação refletiria com maior realidade o valor patrimonial da companhia e não haveria exposição do governo, embora a operação de venda se tornasse mais difícil, por incorporar um ativo de longo prazo.

$\mathrm{Na}$ seqüência, firmaram-se acordo e termo aditivo em dezembro de 1995, pelo qual o saldo remanescente da CRC foi negociado com o governo do Estado do Paraná para ressarcimento em 240 meses $^{15}$.

Ainda com relação à transparência, acompanhando a abertura de capital, a Copel precisou assumir uma postura de especial atenção com relação à divulgação de informações ainda não tornadas públicas, prática comum às sociedades que operam no mercado, com a finalidade de não se caracterizar a pré-venda, o que é exigido pela legislação brasileira e também pela norte-americana, pois tais informações podem ser caracterizadas como confidenciais e influir na determinação do preço das ações.

\section{A preservação do caráter estatal}

Conforme aponta a experiência histórica, a opção pela manutenção de uma empresa estatal está atrelada à opção dos governos, assim como à oferta ou não por parte do agente privado - que tem preferência na prática da atividade econômica -, de forma a atender às necessidades efetivas do país.

Assim foi que houve, em 2001' ${ }^{16}$, uma tentativa de desestatização da empresa, acompanhando outros processos de privatizações que se desenvolviam à época. Esse processo foi desencadeado não como resposta a uma situação deficitária da empresa, mas como expressão de opção de gestão pública federal que se fez acompanhar de medidas adotadas pelos estados.

Não houve a alienação das ações do estado em decorrência da ausência de licitantes - ao que parece, desestimulados ao investimento em razão de grave crise econômica que se alastrava mundialmente e de ambiente de estupor e desconfiança, agravado pelo atentando de 11 de setembro de 2001.

Recentemente a lei autorizadora da alienação foi revogada ${ }^{17}$, acompanhando, novamente, uma tendência política, permitindo que a empresa preserve a condição de sociedade estatal.

\section{Conclusão}

A utilização de sociedade estatal precisará estar alinhada aos princípios esculpidos pela lei, especialmente pela Constituição Federal, com destaque para o princípio da eficiência.

A gestão da sociedade estatal deve pautar-se na garantia de atendimento do interesse público que motivou a sua criação, mas não precisa, necessariamente, ser 
considerada dissociada da rentabilidade, que irá favorecer a busca de investimento privado - no caso das sociedades de economia mista-, e garantir a estabilidade do empreendimento - na empresa mista e na empresa pública.

As sociedades estatais beneficiam-se de diferencial que deve ser explorado por seus administradores, de forma a se otimizar a utilização dos investimentos públicos direcionados à realização da atividade econômica de relevante interesse coletivo ou caracterizada como motivo de segurança nacional.

O diferencial está em sua sujeição ao regime jurídico de direito privado, no que se refere aos mecanismos societários e contratuais utilizados pelos gestores das empresas privadas na busca da melhor opção de gestão possível.

Tais mecanismos aparecem na possibilidade de realização de movimentos societários de transformação, incorporação ou cisão, assim como em mecanismos societário-contratuais, como é o caso do acordo de acionistas e do estabelecimento de golden share, via estatuto da empresa, entre outros, na profissionalização da gestão e no estímulo à progressão dos empregados.

A busca de investidores privados para a aquisição de valores mobiliários também é um recurso acessível à empresa estatal que tenha estrutura de sociedade de economia mista de capital aberto, como adicional de fonte de custeio para as atividades da empresa, permitindo uma desoneração dos já escassos recursos públicos.

No caso da Copel, cujo exemplo é utilizado no capítulo "O caso Copel", oferece-se a demonstração das constatações expostas anteriormente.

Entre os anos 70 e 90, quando nacionalmente a utilização de estatais continua a despontar, a Copel, valendo-se de sua estrutura originária de sociedade anônima de economia mista, parte para a distribuição de suas ações, num primeiro momento de forma associada à democratização da titularidade dos valores mobiliários e como forma de desenvolvimento de políticas tributárias, já que a marca do período não é a busca de parceiros privados, mas a centralização do Estado.

Ainda que, nesse período inicial, parte dos novos acionistas da Copel tenha adquirido essa condição por meio de ações emitidas em decorrência de programa tributário, ao menos a prática de investimento em empresa cumpre sua função de divulgação da possibilidade de aplicação da poupança pública na atividade produtiva empresarial.

Naqueles 20 anos de política de centralização da economia, muitas empresas sofreram grande endividamento em face das necessidades de capitalização, buscada, sobretudo, no mercado internacional, a ponto de ter-se justificado a criação da SEST com o intuito, quanto a essa questão, de contenção do endividamento do setor produtivo estatal.

A Copel, por ser dotada de estrutura societária, teve acesso a outros mecanismos de financiamento, fazendo com que a necessidade de busca de capital estrangeiro não a contaminasse, como contaminou outras estatais. Nessa época, houve recurso ao programa de troca de notas fiscais por ações da companhia, assim como a conversão do Imposto Único Sobre Energia Elétrica, arrecadado pelos municípios, também traduzido em ações. A encampação de pequenas concessionárias trouxe consigo acionistas privados. Tais mecanismos estão relacionados à forma societária da empresa e servem como elemento indicativo das prerrogativas que 
somente podem ser reconhecidas, no setor público, às sociedades estatais.

Num segundo momento, blocos significativos de ações foram negociados, de forma conjugada à emissão de debêntures, fazendo com que, a partir de 1994, a Copel iniciasse uma nova fase, aquela de abertura efetiva de seu capital ao mercado de ações.

No mesmo período, o Brasil e o mundo vivem processos de desestatização, o que visava, conforme já indicado, ao afastamento do Estado da prática econômica. $\mathrm{Na}$ Copel, a opção pela abertura de seu capital para o mercado nacional e americano possibilitou um salto de investimentos para a companhia.

O acesso ao recurso de emissão de valores mobiliários, ao mesmo tempo que permitiu uma necessária injeção de recursos para a empresa, está indissociavelmente ligado à aceitação do seu caráter empresarial, fazendo-se anteceder ou suceder de operações tipicamente contratuais e societárias, como os atos de preparação à oferta pública de ações, a criação de subsidiárias, o acentuado profissionalismo de sua gestão, assim como a adoção de práticas societárias das quais dependem a credibilidade da instituição e a conseqüente aceitação pelo mercado dos valores por ela lançados.
Após uma tentativa de desestatização da empresa em 2001, a Copel manteve sua condição de sociedade estatal de economia mista e de capital aberto, comportando-se como empresa, valendo-se das prerrogativas que caracterizam uma sociedade, mesmo quando suas ações são, em parte, tituladas pelo Estado, e trazendo, em seu objeto, a razão de interesse social que motivou a sua criação e que justifica, sendo esta a opção dos governantes, sua manutenção sob controle estatal.

A gestão de uma empresa estatal poderá encontrar, em mecanismos societários e contratuais disponíveis na disciplina jurídica específica das sociedades, opções que facilitarão seu enquadramento nos patamares de empresa eficiente e permitirão, caso se adote a condição de economia mista, o acesso ao investimento privado como forma de divisão dos encargos que decorrem das constantes necessidades de capitalização, em proveito do interesse de remuneração de tais investidores, mas também - e de muita importância - com o propósito de servir de instrumento do desenvolvimento nacional.

(Artigo recebido em agosto de 2006. Versão final em outubro de 2006)

\section{Notas}

${ }^{1}$ Brasil. Lei no 10.303 , de 31 de outubro de 2001. Altera e acrescenta dispositivos na Lei ${ }^{\circ}$ 6.404, de 15 de dezembro de 1976, que dispõe sobre as sociedades por ações, e na Lei no 6.385 , de 7 de dezembro de 1976, que dispõe sobre o mercado de valores mobiliários e cria a Comissão de Valores Mobiliários. Diário Oficial [da União], Brasília, 1 de novembro de 2001. Disponível em: $<$ http://www6.senado.gov.br/sicon/ExecutaPesquisaLegislacao.action>. Acesso em: 21 nov. 2005. 
${ }^{2}$ Minas Gerais. Tribunal de Justiça do Estado de Minas Gerais. Apelação Civil no 000.199.781-6/00. Southern Electric Brasil Participações x Estado de Minas Gerais. Relator: Des. Garcia Leão. Belo Horizonte, 7 de agosto de 2001. Disponível em: www.tjmg.gov.br. Acesso em: 17 out. 2005.

${ }^{3}$ Brasil. Lei no 8.031 , de 12 de abril de 1990. Cria o programa nacional de desestatização, e dá outras providências. Diário Oficial [da União], Brasília, 13 de abril de 1990. Publicação retificada em 18.4.1990. Disponível em: <http://www6.senado.gov.br/sicon/Executa Pesquisa1 Legislacao.action>. Acesso em: 20 nov. 2005.

${ }^{4}$ Brasil. Lei no 9.457, de 5 de maio de 1997. Altera dispositivos da Lei no 6.404, de 15 de dezembro de 1976, que dispõe sobre as sociedades por ações e da Lei n 6.385 , de 7 de dezembro de 1976, que dispõe sobre o mercado de valores mobiliários e cria a Comissão de Valores Mobiliários. Diário Oficial [da União], Brasília, 6 de maio de 1997. Disponível em: <http:/ /www6.senado.gov.br/ sicon/ExecutaPesquisaLegislacao.action>. Acesso em: 21 nov. 2005.

${ }^{5}$ BrAsil. Lei no 9.491 , de 9 de setembro de 1997. Altera procedimentos relativos ao Programa Nacional de Desestatização, revoga a Lei no 8.031, de 12 de abril de 1990, e dá outras providências. Diário Oficial [da União], Brasília, 10 de setembro de 1997 (Republicada em 11.9.1997). Disponível em < http://www6.senado.gov.br/sicon/ExecutaPesquisaLegislacao.action>. Acesso em: 21 nov. 2005.

${ }^{6}$ Demonstrações Financeiras. Disponível em: http://www.copel.com. Acesso em: 28 out. 2005.

${ }^{7}$ Rodrigues, Claumir Corsi. [Copel: evolução acionária]. Curitiba, 2005. Entrevista concedida em 9 nov. 2005.

${ }^{8}$ Copel, [Diretoria] Curitiba. Ata da Reunião de 8 nov. de 1993.

${ }^{9}$ Paraná. Lei no 10.702 , de 30 de dezembro de 1993. Autoriza, conforme especifica, venda de ações da Copel. Diário Oficial [do Estado do Paraná], Curitiba, Paraná, n. 4.171, de 31 dez. 1993. p. 3-4.

${ }^{10}$ Griebler, Gilberto Serpa. [Carta SGD-C/0509/94] 1994 abr. 7, Curitiba [para] Nestor Celso Imthom Bueno [diretor-geral da Secretaria de Estado da Fazenda].

${ }^{11}$ Paraná. Lei no 11.253, de 21 de dezembro de 1995. Autoriza o Poder Executivo a vender, dar em caução e/ou oferecer como garantia de operações de crédito, financiamentos e operações de qualquer natureza, ações que detém da Companhia Paranaense de Energia - Copel. Disponível em: <http://www.pr.gov.br/casacivil/legislacao.shtml> Acesso em: 11 nov. 2005.

${ }^{12}$ http://www.bndes.gov.br/conhecimento/td/Td-64.pdf. Acesso em: 7 nov. 2005, p. 29.

${ }^{13}$ Idem, p. 30.

${ }^{14}$ Copel, [Conselho de Administração] Curitiba. Ata da Reunião de 13 abr. de 1994.

${ }^{15}$ < http:/ / www.copel.com/relatorio2003/, título 11>. Já foi assinado, em 21/1/2005, o quarto termo de renegociação com o governo do estado, agora no montante de $\mathrm{R} \$ 1,197$ milhões, como se pode ver em <http://www.copel.com/pagcopel.nsf/arquivos/elp404_port/\$FILE/ ELP\%204Q2004\%20port.pdf\#search='conta $\% 20$ resultados $\% 20 \mathrm{a} \% 20$ compensar $\% 20$ copel'>. Acesso em: 10 nov. 2005, p. 4.

${ }^{16}$ Paraná. Lei no 12.355 , de 8 de dezembro de 1998. Autoriza o Poder Executivo a implementar a reestruturação societária da Copel, alienar, dar em caução ou oferecer em garantia ações do estado no capital daquela companhia, bem como contratar operações de crédito, financiamentos ou outras operações por si ou pela Paraná Investimentos S/A e adota outras providências. Diário Oficial [do Estado do Paraná], Curitiba, 9 de dezembro de 1998. Disponível em: <http://celepar7cta.pr.gov.br/SEEG/ sumulas.nsf/319b106715f69a4b03256efc00601826/e74a14ee0c8520b203256e99006892b1? OpenDocument>. Acesso em: 20 nov. 2005. 
${ }^{17}$ Paraná. Lei no 14.608 , de 10 de janeiro de 2005. Revoga dispositivos da Lei no 12.355, de 8 de dezembro de 1998, que autorizou o Poder Executivo a implementar reestruturação societária da Copel, conforme especifica. Diário Oficial [do Estado do Paraná], Curitiba, 28 de janeiro de 2005. Disponível em: <http://celepar7cta.pr.gov.br/SEEG/sumulas.nsf 319b106715f69a4b 03256efc00601826/ 392478666bf9543783256f9d0060828a?OpenDocument>. Acesso em: 20 nov. 2005.

\section{Referências bibliográficas}

Abreu, Jorge Manuel Coutinho de. Curso de direito comercial 1. 2. ed. Coimbra: Almedina, 2002.

Almeida, Fernando Antonio Galvão de; Fioravante, Moacyr Antonio. O papel das empresas estatais. In: Fioravante, Moacyr; Faria, Lauro Vieira de (Orgs.). A última década: ensaios da FGV sobre o desenvolvimento brasileiro nos anos 90. Rio de Janeiro: Fundação Getúlio Vargas, 1993.

Alves, Rosângela do Socorro. Produção de mercado: os contornos da atuação empresarial dos agentes econômicos público e privado e as privatizações. Dissertação. (Mestrado) Programa de Pós-Graduação em Direito da Universidade Federal do Paraná.

Amaral Filho, Marcos Jordão Teixeira do. Privatização no Estado contemporâneo. São Paulo: Ícone, 1996.

Ataliba, Geraldo. Empresa estatal delegada de serviço público tem superávit ou déficit (não é devedora da contribuição social sobre o lucro). Revista de Direito Administrativo, Rio de Janeiro, n.200, p. 348-362, abr./jun. 1995.

BAER, Werner. A economia bra\$sileira. São Paulo: Nobel, 1996.

Bielschowsky, Ricardo. Pensamento econômico brasileiro: o ciclo ideológico do desenvolvimentismo. 3. ed. Rio de Janeiro: Contraponto, 1996.

Biondi, Aloysio. O Brasil privatizado: um balanço do desmonte do Estado. São Paulo: Fundação Perseu Abramo, 2003.

Boeker, Paul H. Abertura econômica da América Latina e a redescoberta do investimento externo. In: BoEker, Paulo H. (Org). Transformações na América Latina: privatização, investimento estrangeiro e crescimento. Rio de Janeiro: Jorge Zahar, 1995.

Brum, Argemiro J. O desenvolvimento econômico brasileiro. 9.ed. rev. e atual. Petrópolis: Vozes, 1990.

Caetano, Marcello. Manual de direito administrativo. 10.ed. rev. e actual. pelo Prof. Dr. Diogo Freitas do Amaral. Tomo 2. Coimbra: Almedina, 1997.

Carvalhosa, Modesto. Comentários à lei de sociedades anônimas: Lei 6.404, de 15 de dezembro de 1976, com modificações das Leis no 9.457, de 5 de maio de 1997, e no 10.303, de 31 de outubro de 2001. São Paulo: Saraiva, 2002. 
Casagrande Neto, Humberto. Abertura de capital de empresas no Brasil: um enfoque prático. $3^{a}$ ed. São Paulo: Atlas, 2000.

Cassagne, J. C. Derecho administrativo. 4. ed. Buenos Aires: Abeledo-Perrot, 1993.

CHIRILlo, Eduardo J. Rodriguez. Privatizacion de la empresa publica y postprivatizacion: analisis juridico. Buenos Aires: Abeledo-Perrot, 1995.

Derani, Cristiane. Privatização e serviços públicos: as ações do Estado na produção econômica. São Paulo: Max Limonad, 2002.

Di Pietro, Maria Sylvia Zanella. Direito administrativo. 16. ed. São Paulo: Atlas, 2003.

Dweck, Ruth Helena. O movimento de privatização dos anos oitenta: reais motivos. Nova Economia: Revista do Departamento de Ciências Econômicas da UFMG. Belo Horizonte, v.10, n.2, p.145-170, dez. 2000.

Figueiredo, Lúcia Vale. Curso de direito administrativo. 6.ed. rev. atual. e ampl. São Paulo: Malheiros, 2003.

Gabardo, Emerson. Princípio constitucional da eficiência administrativa. São Paulo: Dialética, 2002.

Galgano. Francesco. Derecho comercial: el empresário 1. Tradução de Jorge Guerrero. Santa Fé de Bogotá: Ed. Temis, 1999.

Hachette, Dominique; Luders, Rolf. A aceleração do ritmo da privatização na América Latina. In: Boeker, Paul H. (Org.). Transformações na América Latina: privatização, investimento estrangeiro e crescimento. Rio de Janeiro: Jorge Zahar, 1995.

Ianni, Octávio. Estado e planejamento econômico no Brasil. 5.ed. rev. e atual. Rio de Janeiro: Civilização Brasileira, 1991.

Justen FILHo, Marçal. Comentários à lei de licitações e contratos administrativos. 8.ed. São Paulo: Dialética, 2000.

LeÃes, Luiz Gastão Paes de Barros. Direito comercial: textos e pretextos. São Paulo: José Bushatsky, 1976.

Martins, Luciano. Estado capitalista e burocracia no Brasil pós-64. Rio de Janeiro: Paz e Terra, 1985.

Melo, Giselle L. de O. L. A função social da empresa como parâmetro de legalidade. Revista de Direito Empresarial, Curitiba, v. IV, p. 277-320, jul./dez. 2005.

Modesto, Paulo. Notas para um debate sobre o princípio da eficiência. Revista Trimestral de Direito Público, São Paulo, n.31, p.54, 2000.

OrME JR., William A. A aceleração do ritmo da privatização na América Latina. In: BoEKER, Paul H. (Org.). Transformações na América Latina: privatização, investimento estrangeiro e crescimento. Rio de Janeiro: Zahar, 1995.

Pelegrino, Carlos Roberto. Regime jurídico das empresas estatais. Revista de Direito Público, São Paulo, n.83, p. 149, jul./set. 1987.

PInHeIRo, Armando Castelar. Privatização no Brasil: por quê? Até onde? Até quando? In: Giambiagi, Fábio; Moreira, Maurício Mesquita (Orgs.). A economia brasileira nos anos 90. Rio de Janeiro: BNDES, 1999. 
Pinheiro, Armando Castelar; Giambiagi, Fábio. Os antecedentes macroeconômicos e a estrutura institucional da privatização no Brasil. In: PINHEIro, Armando Castelar; FuKASAKu, Kuchiro (Orgs.). A privatização no Brasil: o caso dos serviços de utilidade pública. Rio de Janeiro: BNDES, 1999.

PINTO, Bilac. O declínio das sociedades de economia mista e o advento das modernas empresas públicas. Revista Forense, Rio de Janeiro, v.146, p. 9-17, mar./abr. 1953.

Prado, Sérgio. Aspectos federativos do investimento estatal. In: Affonso, Rui de Britto Álvares; SILVA, Pedro Luiz Barros (Orgs.) Empresas estatais e federação. São Paulo: Fundap, 1996.

Ramamurti, Ravi. A privatização como remédio para empresas estatais. In: Boeker, Paul H. (Org.). Transformações na América Latina: privatização, investimento estrangeiro e crescimento. Rio de Janeiro: Jorge Zahar, 1995.

Redi, Maria Fernanda de Medeiros. Sociedades de economia mista e lucratividade Instituto de Resseguros do Brasil - IRB: um exemplo real. Revista Trimestral de Direito Público, São Paulo, n.33, p. 185-206, 2001.

REZENDE, Fernando. O crescimento (descontrolado) da intervenção governamental na economia brasileira. In: Seminário Sobre Planejamento e Controle do Setor de Empresas Estatais: Casos Nacionais. Brasília: Ipea-Nações Unidas, 1983.

Ribeiro, Marcia Carla Pereira. Sociedade de economia mista e empresa privada: estrutura e função. Curitiba: Juruá, 2001.

Salomão Filho, Calixto. O novo direito societário. São Paulo: Malheiros, 1998.

SouzA, Washington Peluso Albino de. Direito econômico. São Paulo: Saraiva, 1980.

Sundfeld, Carlos Ari. Entidades administrativas e noção de lucro. Revista Trimestral de Direito Público, São Paulo. n. 6, p.263-268, abr./jun. 1994.

Reforma do Estado e empresas estatais: a participação privada nas empresas estatais. In: Sundfeld, Carlos Ari (Org.). Direito administrativo econômico. São Paulo: Malheiros, 2000.

TÁcito, Caio. O retorno do pêndulo: serviço público e empresa privada: o exemplo brasileiro. Revista de Direito Administrativo, Rio de Janeiro, n. 202, p.1-10, out./dez. 1995. Werneck, Rogério L. F. Empresas estatais e política macroeconômica. Rio de Janeiro: Campus, 1987. 


\section{Resumo - Resumen - Abstract}

\section{Mecanismos societários e contratuais de gestão das sociedades estatais Marcia Carla Pereira Ribeiro e Gísela Dias Chede}

As sociedades estatais são importantes organizações societárias, que podem servir ao administrador público para a realização de atividades econômicas que configurem relevante interesse coletivo ou motivo de segurança nacional. Com a finalidade de adequarem-se aos limites de investimento público e com vistas ao cumprimento do princípio da eficiência, elas podem utilizar-se de mecanismos societários e contratuais de gestão disponibilizados a empresas, sejam elas estatais ou privadas. Os movimentos societários, os mecanismos de controle e partilha de controle e a adoção das práticas de governança corporativa são alternativas jurídicas disponibilizadas aos administradores das empresas estatais. A análise do caso da Companhia Paranaense de Energia Elétrica (Copel) é realizada no artigo com o propósito de auxiliar na visualização da aplicação de tais institutos.

Palavras-chave: sociedades estatais, mecanismos jurídicos, gestão.

\section{Mecanismos societarios y contractuales de gestión de las sociedades estatales Marcia Carla Pereira Ribeiro e Gísela Dias Chede}

Las sociedades estatales son importantes organizaciones societarias que pueden servir, al administrador, a la realización de actividades económicas que configuren interés colectivo relevante o motivo de seguridad nacional. Con la finalidad de adecuarse a los límites de inversiones públicas, y con vistas al cumplimiento del principio de la eficiencia, en esta actividad pueden utilizarse mecanismos societarios y contractuales de gestión disponibles a las empresas, sean ellas estatales o privadas. Los movimientos societarios, los mecanismos de control y reparto del control y la adopción de las prácticas de gobernabilidad corporativa son alternativas jurídicas disponibles a los administradores de empresas estatales. Este artículo tiene el objetivo de analizar el caso de la Compañía Paranaense de Energía Eléctrica (Copel) con el propósito de auxiliar en la visualización de la aplicación de tales institutos.

Palabras-clave: sociedades estatales, mecanismos jurídicos, gestión.

\section{Corporate and contractual mechanisms in the management of state-owned enterprises} Marcia Carla Pereira Ribeiro e Gísela Dias Chede

State-owned enterprises are important corporate organizations that can be of use to perform relevant economic activities related to collective interests or national security issues. In order to conform themselves to public investment constraints and fulfil the principle of efficiency, there is a number of legal and contractual management mechanisms to both public and private corporations. Legal transactions, corporate control mechanisms and the sharing of control, as well as the adoption of corporate governance practices are legal alternatives put in place to the managers of public corporations. The case analysis of Electrical Power Utility of the State of Paraná (Copel) tries to illustrate the use of such mechanisms.

Key words: state-owned enterprises, legal mechanisms, management.

Marcia Carla Pereira Ribeiro

Professora doutora da Faculdade de Direito da UFPR, professora titular de Direito Societário da PUCPR, procuradora do Estado do Paraná. Contato: <marcia.carla@terra.com.br>

Gísela Dias Chede

Procuradora do Estado do Paraná. Contato: <gis-chede@pge.pr.gov.br> 